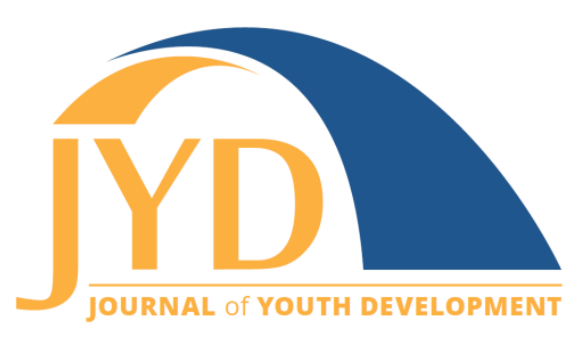

http://jyd.pitt.edu/ | Vol. 15 Issue 1 DOI 10.5195/jyd.2020.827 | ISSN 2325-4017 (online)

\title{
Creating Community Through Cohort Learning: A Training Model for Youth Development Professionals
}

\author{
Amber Shanahan \\ University of Minnesota Extension, Center for Youth Development \\ shanahan@umn.edu \\ Trisha Sheehan \\ University of Minnesota Extension, Center for Youth Development \\ tsheehan@umn.edu
}

\begin{abstract}
University of Minnesota Extension Center for Youth Development (CYD) initiated a learning cohort for their local youth development professionals, 4-H Extension educators (EEs) to fulfill a need to better support staff beyond onboarding. The Youth Development Learn and Lead (YDLL) cohort is grounded in integrative leadership that influences professional relationship building through the sharing of applicable skills and theory across hierarchical boundaries while providing a community of practice to discuss ideas and share resources. The cohort has positively impacted employee engagement and has shown impressive results around networking, relationship building, and learning objectives. The YDLL cohort has been deemed an essential training by CYD, and has been replicated internally to encompass a larger audience with unique staff development needs.
\end{abstract}

Key words: cohorts, action learning, onboarding, staff development

\section{Reviewing Past Training Practices}

The University of Minnesota Extension's Center for Youth Development (CYD) is a large youthserving organization that delivers positive youth development programming through community-based 4-H programs. 4-H is rooted in experiential learning (Kolb, 1984) and emphasizes a "learn by doing" approach that focuses on belonging (feeling cared about and

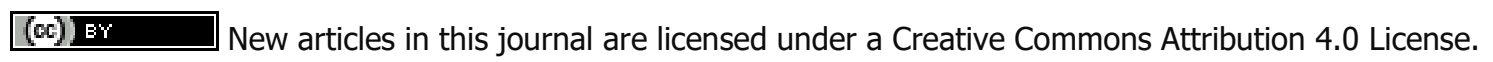
This journal is published by the University Library System, University of Pittsburgh and is cosponsored by the University of Pittsburgh Press. The Journal of Youth Development is the official peer-reviewed publication of the National Association of Extension 4-H Youth Development Professionals and the National AfterSchool Association. 


\section{Youth Development Workforce}

establishing a sense of connection within a group), independence (making decisions and taking action), generosity (finding meaning and purpose through community involvement), and mastery (experiencing success in solving problems and meeting challenges (Kress, 2004). CYD's programming is guided by two main program goals: Youth will learn by developing a passion in their areas of interest and youth will lead by being innovators and social change agents (Skuza, Grant, Harrington, Haugen, \& Pokorney, 2016).

Minnesota's 4-H program is supported by local Extension educators (EEs) who are based in counties and tribal communities throughout Minnesota. The role requires comprehension of and the ability to execute a diverse range of responsibilities, including (but not limited to) volunteer placement and training, member recruitment and support, design and delivery of youth programs and events, marketing and promotion, evaluation, and financial management.

Onboarding for new EEs provides an opportunity to learn the culture and language of the 4-H program, the Extension system, and the University of Minnesota. Onboarding topics are intended to offer a comprehensive knowledge base and understanding of the EE work. Historically, the process was led within a regional context due to the expansive size of the state; CYD is broken into five distinct geographic regions across Minnesota and each region independently determined the most efficient way to deliver onboarding to new employees. The 6-month process consisted of quick (often online) check-ins with delivery facilitated by content experts. The meetings were typically constructed as one-way information sharing sessions.

While onboarding did serve a need to provide introductory training to staff in a cost-effective manner, the process typically lacked opportunities to engage with a sustained community of peers and practitioners where reflection, leadership, and improved practices could be applied and challenged. This lack of long-term training and community-based follow-through is consistent with many youth development organizations (Hill, Connolly, Akiva, \& McNamara, 2018). When the 6 months of onboarding was complete, regularly scheduled training came to a brisk end.

\section{Assessing Training Needs}

Through data collected via an online survey administered by CYD's staff development team, EEs claimed to feel overwhelmed with the intensity of information shared throughout onboarding and the timing for which it was delivered; much of the information shared was perceived as 


\section{Youth Development Workforce}

excessive due to limited opportunities for immediate application. For example, fiscal management materials shared during onboarding might not actually be useful until budgets are due, which could be months from when the onboarding session took place. Without ample, direct opportunities to utilize the content shared, the information was not adequately retained by EEs.

The evaluative feedback also noted inconsistencies in regional delivery methods that led to varied levels of understanding from region to region; some regions spent more time on a specific topic than others, so dependability of how EEs interpreted and executed policies or processes was worrisome.

In addition, research shows that educators often experience disillusionment in their role around their sixth month of employment (Moir, 1990). EEs validated this research by reporting the abrupt end of onboarding at Month 6 was a challenge; local EEs are often the only youth development professional in their office and are isolated in both personal connection and geographic proximity to colleagues. With limited opportunities to connect with colleagues after onboarding ended, EEs expressed a sense of seclusion in their remote county and office settings, leading to a decreased sense of organizational belonging. The onboarding process itself was already limited in face-to-face interaction; once the onboarding process was complete, peer interface opportunities were few and far between.

Finally, when asked what they most valued in staff development opportunities, EEs provided the following qualitative feedback:

- Being given time to share/talk/converse about programs and having the time set aside to build on those relationships that are forming.

- I like to interact with others and share ideas, and this is easier in a face-to-face training.

- Meeting with fellow colleagues to share ideas about events, activities, and things we can do together as a team is helpful.

- I think our staff development should follow our "learn by doing" motto. When we have the time to engage with each other and use each other as resources we need to maximize that opportunity.

Overall, the results of the evaluation highlighted that EEs were not satisfied with the training received during onboarding and furthermore, were feeling less organizational engagement due to their perceived lack of continued support and their inability to connect frequently with 


\section{Youth Development Workforce}

colleagues. The evaluation results demonstrated a need to reexamine onboarding practices, and also emphasized an opportunity to build upon initial training with expansive, consistent, and tangible long-term engagement opportunities. The feedback also highlighted a desire to connect more frequently face-to-face and to intertwine intentional opportunities for peer interface.

This article will outline the design and subsequent modification of an 8-month learning cohort for youth development professionals that allows for the development of professional relationships and applicable sharing of resources and the impact it has had on both the participants' employee engagement and the organization's comprehensive training structure.

\section{The Benefits of Cohort Learning}

Cohorts are known to provide participants with a greater feeling of inclusiveness while promoting collaboration, and this is especially critical when participants are situated at a distance from their organizational hub (Brooks, 1998). In the case of CYD, the organizational hub is Saint Paul, Minnesota and employees are situated up to 450 miles away from this campus base. CYD championed a cohort-learning model of delivery to provide long-term, sustained support to local EEs regardless of geographic complexities. The proposed cohort would focus on a fixed-group of participants who were hired on a relatively similar timeline. Limiting the cohort to a select group of new hires who bring comparable proficiency to the experience enhances professional learning and skill development (Barnett, Basom, Yerkes, \& Norris, 2000; Reynolds \& Hebert, 1998; Peel, Wallace, Buckner, Wrenn, \& Evans, 1998) because it creates a learning environment where all participants experience a sense of belonging (feeling valued and accepted), understand their collective purpose (sharing common commitment and goals), and actively and purposefully engage in group learning activities (recognizing the value of interdependence and interaction) (Barnett et al., 2000).

When staff support is perceived as inadequate, turnover is higher, and the need to hire and train new staff continually increases (Hartje, Evans, Killian, \& Brown, 2008), so supporting staff development is a cost-effective solution for youth development organizations (Wiedow, 2018). But the benefits of providing a community of practice (COP) for staff is more than just the assumption that engaged staff will remain in their roles longer, limiting the cost of hiring. Cohort's that act as CoPs-a group of people who share a concern or passion for something they do and learn how to do it better as they interact regularly (Wenger, 2011)-can enable 


\section{Youth Development Workforce}

improved performance (Kerno \& Mace, 2010), assumingly translating to the execution of reliable, quality youth programming.

\section{Cohort Development}

The cohort was dubbed the Youth Development Learn and Lead (YDLL) cohort and was piloted in 2015. It was designed to influence the engagement and retention of local EEs through the following objectives, notably focused on networking and relationship building, determined based on feedback from EEs:

1. Enhance professional youth worker relationships and foster a learning community through networking and collaborative activities.

2. Influence professional relationship-building through the sharing of applicable skills and theory, and by providing a community of practice to discuss ideas and share resources.

3. Build tangible skills that can be applied immediately to their EE position.

4. Deliver relevant and research based information.

In the interest of creating a place of employment where staff feel engaged, supported, and satisfied, CYD intertwined EE voice into every aspect of the cohort. The underlying philosophy of a cohort is that learners become empowered and have a sense of ownership for their own professional development (Brooks, 1998). The incorporation of participatory leadership practices (open space technology, World Café, etc) that provide space for facilitated dialogue and informal discussion and allow participants to co-lead throughout the experience leads to participants owning a stake in the experience.

Because an emphasis on participatory leadership is significant to the YDLL structure, and social capital is vital for leadership development programs (Norman, 2013), the cohort adopted a hybrid design to safeguard participant involvement. Sessions are offered both face-to-face and online to support continuous connection throughout the duration of the cohort while limiting travel time and expense related to in-person meetings. An overview of the design and objectives of YDLL is shown in Table 1. 
Table 1. Overview of YDLL Objectives and Cohort Design

\begin{tabular}{l|l}
\hline YDLL cohort objectives a & $\begin{array}{l}\text { Designing the learning environment to } \\
\text { meet cohort objectives }\end{array}$ \\
\hline $\begin{array}{l}\text { Enhance professional youth worker relationships } \\
\text { and foster a learning community through } \\
\text { networking and collaborative action learning } \\
\text { activities. }\end{array}$ & $\begin{array}{l}\text { The 8-month cohort is offered both face-to-face } \\
\text { and online, providing continuous hybrid } \\
\text { connectivity to enhance colleague cohesion. }\end{array}$ \\
\hline $\begin{array}{l}\text { Influence professional relationship networks } \\
\text { through the sharing of applicable skills and theory } \\
\text { by building a community of practice to discuss ideas } \\
\text { and share resources. }\end{array}$ & $\begin{array}{l}\text { A participatory leadership approach creates a } \\
\text { platform where participants share collective }\end{array}$ \\
$\begin{array}{l}\text { talents and experiences and ensures participant } \\
\text { contribution. }\end{array}$ \\
\hline $\begin{array}{l}\text { Build tangible skills that can be applied immediately } \\
\text { to the EE position through the delivery of relevant } \\
\text { and research-based information. }\end{array}$ & $\begin{array}{l}\text { CYD staff facilitate sessions based on pertinent } \\
\text { and timely YD topics using research-based } \\
\text { curricula. }\end{array}$ \\
\hline $\begin{array}{l}\text { Creating a welcoming and comfortable space } \\
\text { informed by participatory leadership is } \\
\text { imperative to the success of this design. }\end{array}$ \\
\hline
\end{tabular}

a YDLL cohort objectives were determined based on feedback from EEs.

\section{Structure of the YDLL Cohort}

The YDLL cohort spans an 8-month time period and consists of four face-to-face 2-day meetings and four online sessions. Along with creating a welcoming space for colleagues to connect and create a CoP, the YDLL cohort has the capacity to support staff by extending, deepening, and aligning the learning they recently received during the onboarding process. Unlike historical onboarding practices where topics were shared regardless of their immediate relevance, the YDLL cohort delivers content that is crucial to work taking place in real time where there are ample opportunities for EEs to practice and utilize that knowledge in a tangible, timely way. Additionally, CYD was able to capitalize on the pre-scheduled cohort time with staff to infuse brief exposure to signature CYD curricula usually offered as optional trainings for EEs. 


\section{Youth Development Workforce}

The cohort platform is used to promote these optional offerings so participants can partake in larger dose trainings should their interest be piqued.

A variety of topics-determined in partnership with the CYD staff development team and local EEs-are addressed throughout the cohort experience. They are strategically scheduled to coincide with where the EEs are each month in their process of learning and executing their new position. The following list is a sampling of cohort topics:

- Strengths-Based Leadership

- YD Program Quality

- Crucial Conversations

- Volunteer Development

- Operational topics - finances, risk management, etc.

- Dilemmas in Youth Work

- Evaluation and Impact Reporting

- Program Planning

- Relationship Building \& Partnerships

- Positive YD \& Engaging Youth

- Leadership \& Supervision in a YD context

Internal CYD colleagues are recruited to deliver and facilitate the topics noted based on their expertise. Using internal colleagues builds upon the participatory leadership framework, ensuring many levels of leadership are represented at the table while creating a space for participants to engage and connect with colleagues they might not work with on a regular basis. Centralizing the delivery ensures consistency in the messages being shared.

\section{Participatory Leadership in Action-Action Learning Projects}

Professional development that encourages collective participation and professional communication among participants tends to produce better outcomes (Cochran-Smith \& Lytle, 1999; Finley, Marble, Copeland, Ferguson, \& Alderete, 2000; Garet, Porter, Desimone, Birman, \& Yoon, 2001), and opportunities for participants to make connections to practice through reflection and active learning leads to stronger coherence (Hill et al., 2018). To provide an intentional space where EEs can immediately apply their learning, the cohort has enacted the use of an action learning project (ALP). Action learning is an experiential approach to learning that focuses more on what one does not know (Kinsey, 2011). Pairing a cohort model with action learning affords participants a designated platform for responding more effectively to 


\section{Youth Development Workforce}

change while developing creative, flexible, and successful strategies in partnership with colleagues (Shanahan, 2018).

Participants choose a project based on a pressing issue or idea from their local program context, bringing value and buy-in to the process. Each project centers on a real opportunity of significance to the organization, addresses a persistent leadership issue, or is a new organizational development activity.

A local EE from Northern Minnesota recognized a need for more intentionality around partnership development between 4-H and community school districts. She set an ALP goal to increase after-school offerings with partner schools that had a significantly higher free and reduced-price lunch percentage compared to the state average. This EE used the ALP process to set accountability deadlines and to push herself on a project that might otherwise have settled to the bottom of her "to do" pile.

Participants connect with small sub-groups of peers monthly to check in, share resources, ask insightful questions, and participate in reflective listening, all of which are essential elements of action learning (Kinsey, 2011). An optional mentor component is available as well, pairing YDLL participants with CYD staff who are well positioned to support them on the ALP journey. Mentors provide desired insight and resources for the participant while further building opportunities to connect EEs with experienced colleagues (Shanahan, 2018).

Participants present their ALP and subsequent leadership growth during the final session to an audience of peers and CYD leadership. From 2015 to 2019 there were 65 staff members who participated in the ALP process and 58 who completed the cohort in its entirety, all of whom believed the ALP process was useful in their work; many claimed the ALP as the single greatest takeaway of the entire cohort experience.

Referring back to the northern Minnesota example, this local EE presented her success establishing an after-school photography program that far-surpassed the enrollment goal originally indicated, and she outlined the leadership growth she experienced through engaging in new community initiatives and forming partnership networks. 


\section{YDLL Cohort Impacts}

Of the $58 \mathrm{EEs}$ who took part in and completed the YDLL series from 2015 through 2019, 50 (86\%) responded to a request to complete a post-cohort online evaluation of the cohort learning process. Overall, the YDLL cohort has shown impressive results:

- $\mathbf{9 8 \%}$ of participants felt the cohort enhanced colleague relationships and fostered a learning community through networking and collaborative activities.

- $100 \%$ of participants said the cohort led to heightened employee engagement through relationship-building and the sharing of applicable skills; theory; and providing a community of practice to test knowledge, discuss ideas, and share resources.

- $\mathbf{9 4 \%}$ of participants felt they received relevant and research-based YD content.

- $\mathbf{9 6 \%}$ of respondents from the 2018-2019 cohorts noted that this learning experience positively influenced their overall engagement in CYD. (Data were collected in 2018 and 2019 only.)

Respondents believed the cohort model provides crucial value to the training context. Their appreciation of the cohort design of this learning environment is exemplified in the following comments:

- I have felt a part of a unique group where we became comfortable sharing our highs and lows and sharing ideas to help better our county programs. I simply loved our face-to-face meetings and being able to mix and mingle with the other EE who were "new" to the position just like me and to grow together.

- The networking alone was totally worth it.

- In our jobs we have such limited contact with our colleagues. This was a great way for me to get to know other EE's who have been here for a similar amount of time. It is a good way to reframe expectations and to see and be inspired by what others are doing.

- Relationship building is key to success in this job and being able to personally connect with peers is very necessary to stay motivated in this role when you are a single EE county.

- I feel a huge part of our work is learning to collaborate in order to make our work the best it can be and this process helped by getting to meet other people from around the state that you might not otherwise work with.

The YDLL cohort is also one tool being implemented by CYD in response to the University of Minnesota's commitment to employee engagement. The University conducts an annual survey 


\section{Youth Development Workforce}

of employees, asking them to rate their agreement with statements about their workplace environment. Table 2 includes a sample of statements from the 2017 University-wide survey and matches them with explicit ways the cohort is addressing these challenges.

\section{Table 2. Comparison of University of Minnesota Employee Engagement Survey Statements and YDLL Strategies to Address those Needs}

\begin{tabular}{|l|l|l|l}
$\begin{array}{l}\text { Engagement statements from } \\
\text { the employee engagement } \\
\text { survey }\end{array}$ & $\begin{array}{l}\text { Cohort strategies to respond to engagement needs-what } \\
\text { the cohort is doing to actively doing to address employee } \\
\text { engagement concerns }\end{array}$ \\
\hline $\begin{array}{l}\text { "I have trust and confidence in my } \\
\text { college's leadership team." }\end{array}$ & $\begin{array}{l}\text { The cohort is addressing this opportunity by connecting members } \\
\text { of the leadership team to EE participants more regularly, } \\
\text { providing space for crucial conversations to occur. }\end{array}$ \\
\hline $\begin{array}{l}\text { "I have the resources I need to do } \\
\text { my job effectively." }\end{array}$ & $\begin{array}{l}\text { The cohort is being co-built with EEs to ensure resources and } \\
\text { topics of high priority for the role are incorporated into the } \\
\text { experience. }\end{array}$ \\
\hline $\begin{array}{l}\text { "My department uses innovative } \\
\text { approaches to improve internal } \\
\text { effectiveness." }\end{array}$ & $\begin{array}{l}\text { The cohort model itself is an innovative framework for training } \\
\text { within CYD and is focused on providing tangible, effective training } \\
\text { that can be applied immediately to the EE role. }\end{array}$ \\
\hline
\end{tabular}

In response to the 2017 engagement survey data, cohort designers put extra effort into how the cohort can support employee engagement within CYD, putting thoughtful energy into ways to cultivate a space where staff feel welcome and prepared. Coffee and snacks are always available, the room set-up is prime for participatory engagement, and music plays to hearten the space as participants arrive. The significance of these gestures was positively noted in endof-series feedback.

From the 2017 cohort experience, $100 \%$ of participants agreed that:

- Participation in the cohort positively influenced my overall engagement in my role.

- I had the opportunity to share my thoughts and opinions.

- I feel more prepared to execute the local EE role than I did prior to my participation in the cohort. 


\section{Youth Development Workforce}

- The cohort was a welcoming space.

- Since participating in the cohort, I have an increased sense of belonging with CYD.

Though the cohort has not been able to explicitly address and resolve employee retention concerns, it has been successful in ensuring people identify CYD as a great place to work. During a recent exit interview with a representative from CYD leadership, a past YDLL member shared that the cohort experience was a valuable training that led to knowledge and relationships that will translate to future positions.

\section{Modification of the Cohort}

Feedback regarding the overall purpose and objectives of cohort use for ongoing training is consistently positive, yet participants regularly request specific tweaks to schedules, topics, and technology formats to warrant value and relevance. No two cohorts have ever looked exactly the same. The program design of the cohort model is responsive, and improvement and modification of each subsequent cohort series is informed by feedback and insight gathered from graduated participants to ensure the training remains relevant and valuable for future participants. Subsequently, the annual adjustments lead to variance in the post-evaluative tools. Because of the evaluative inconsistency, participant voice is a key element of the cohort programmatic design; the annual planning process relies heavily on qualitative feedback collected during roundtable discussion.

\section{Next Steps}

The success of the initial YDLL cohort model proved that cohort learning is the preferred model of training delivery for most of CYD's local YD professionals. This realization emphasized the need to establish cohorts of learning as the ongoing, long-term model of staff development, beginning once a local EE is hired and following their trajectory into experienced-staff status (4 or more years onboard). To meet this need, the CYD staff development team proposed the implementation of a three-tiered cohort model that would take place throughout the first 5 years of employment: (a) an onboarding cohort (from hire until month 6 of employment), (b) YDLL cohort (after 6 months of employment), and (c) experienced staff cohort (after 4 years in their role). 
A transformed onboarding cohort was piloted in 2018 and consisted of a series of intentional learning opportunities delivered in a consistent manner through campus sessions and webinars. This new process removed the expectation for onboarding to be led regionally, subsequently eliminating the inconsistencies of previous practices, though support is still offered regionally in an effort to build colleague cohesion. The onboarding cohort is comprised of new hires from every region, and all of the trainings are facilitated centrally.

The original YDLL cohort continues to fill a void for local EEs to form CoPs through relationship building, receive training on relevant professional development topics of their choice, and provides exposure to leadership opportunities via the ALP. The YDLL cohort ensures that opportunities to connect with colleagues continue beyond the crucial 6-month mark of employment.

The experienced staff cohort (dubbed the Sustain cohort) was developed based on feedback from tenured EEs who were also yearning to feel more connected with colleagues, but had not yet had an opportunity to participate in a cohort. In fact, it was the insight of the now experienced staff that influenced the initial creation of the cohort system. Sustain was piloted in 2018 and followed a similar structure as YDLL, but is focused on advanced topics more pertinent and specific for long-term staff. For example, one iteration of the Sustain cohort emphasized volunteer support and engagement; the training creates a CoP for local EEs who have significant experience to bring to the table and are committed to increasing their ability to successfully manage a team of volunteers.

Further evaluation is needed to understand the impact of the three-tiered cohort structure, but CYD is optimistic that this extended model of colleague cohesion will instill a welcoming sense of belonging to CYD employees from Day 1 , leading to higher employee retention and more positive employee engagement.

\section{Challenges}

Minnesota is a geographically large state, so the cost and time associated with attending faceto-face gatherings must continually be examined. While some organizations might refrain from using a face-to-face cohort model because of funding requirements (Beder \& Medina, 2001), CYD recognizes the value of the face-to-face aspects of YDLL; the relationships formed and the knowledge gained while meeting together physically have outweighed the monetary investment of travel. 
Participation in the cohort relies on an investment of time, which can be difficult for staff who do not work full time or who have local stakeholders that question their time away from the office. To tackle this challenge, it is imperative that cohort designers communicate the benefits of this training with participants and local stakeholders alike; there must be an intentional plan to inform parties on how participation will build a local EE's capacity to enhance their work in the local program.

As noted under modifications, YDLL designers continue to update the cohort design based on participant feedback, and also need to remain cognizant of challenges posed by EEs, including time and cost constraints of travel and participation and continual shifting of staff needs.

Finally, not all CYD EE roles are created equal; some participants have unique positions within a county and therefore not all of the cohort topics relate to their individual role. Cohort designers must remain aware of each staff's needs to ensure cohort content benefits their development and position to the fullest.

\section{Recommendations}

For the purposes of supporting extended training to youth development staff, especially when remote office settings are a factor, a cohort-learning model is a preferred model of learning. Cohorts enhance professional youth worker relationships and foster a learning community through networking and collaborative activities, influence professional relationship building through the sharing of applicable skills and theory, and provide a CoP to discuss ideas and share resources. The infusion of participatory leadership practices builds on a participant's existing expertise and strengths. The use of an ALP encourages participants to share their work and reflect on their leadership trajectory.

The cohort model has built a deliberate, cohesive community of youth development practice that intertwines essential training and action learning, and CYD staff experience a heightened sense of belonging to an organization that is excited to invest in their staff development, leading to positive employee engagement. This model certainly has potential to positively impact staff development practices in other youth-serving organizations where remote work situations limit face-to-face connectivity. 
Youth Development Workforce

\section{References}

Barnett, B. G., Basom, M. R., Yerkes, D. M., \& Norris, C. J. (2000). Cohorts in educational leadership programs: Benefits, difficulties, and the potential for developing school leaders. Educational Administration Quarterly, 36(2), 255-282.

Beder, H., \& Medina, P. (2001). Classroom dynamics in adult literacy education (Report No. 18). Boston, MA: National Center for the Study of Adult Learning and Literacy.

Brooks, P. A. (1998). Cohort communities in higher education: The best example of adult education. Adult Education Research Conference. http://newprairiepress.org/aerc/1998/papers/12

Cochran-Smith, M., \& Lytle, S. L. (1999). Relationships of knowledge and practice: Teacher learning in community. Review of Research in Education, 24(1), 249-305. https://doi.org/10.3102/0091732X024001249

Finley, S., Marble, S., Copeland, G., Ferguson, C., \& Alderete, K. (2000). Professional development and teachers' construction of coherent instructional practices: A synthesis of experiences at five sites. Promoting Instructional Coherence, 19(2), 74-86. http://www.sedl.org/pubs/pic04/welcome.html

Garet, M. S., Porter, A. C., Desimone, L., Birman, B. F., \& Yoon, K. S. (2001). What makes professional development effective? Results from a national sample of teachers. American Educational Research Journal, 38(4), 915-945. https://doi.org/10.3102/00028312038004915

Hartje, J., Evans, W., Killian, E., \& Brown, R. (2008). Youth worker characteristics and self-reported competency as predictors of intent to continue working with youth. Child and Youth Care Forum, 371), 27-41. https://doi.org/10.1007/s10566-007-9048-9

Hill, S., Connolly, J., Akiva, T., \& McNamara, A. (2018). Taking it to a new level: inquiry-based professional development as a field-building enterprise. In H. J. Malone \& T. Donahue (Eds.), The growing out-of-school time field: Past, present, and future (pp. 115-117). Charlotte, NC: Information Age.

Kerno, S. \& Mace, S. (2010). Communities of practice; beyond the team. Advances in Developing Human Resources, 12(1), 78-92. https://doi.org/10.1177/1523422310365341

Kinsey, S. (2011). Action learning-An experiential tool for solving organizational issues. Journal of Extension, 49(4), Article 4TOT2. https://www.joe.org/joe/2011august/tt2.php

Kolb, D. A. (1984). Experiential learning: Experience as the source of learning and development (Vol. 1). Englewood Cliffs, NJ: Prentice-Hall.

Kress, C. (2004). Essential elements of 4-H youth development. https://4-h.org/wpcontent/uploads/2016/02/TheEssentialElementsof4HYouthDevelopment.pdf

Moir, E. (1990). Phases of first-year teaching. https://www.aliefisd.net/cms/lib011/TX01917308/Centricity/Domain/140/First\%20Year\%20Teach er\%20Phases\%20Article.pdf 
Journal of Youth Development | http://jyd.pitt.edu/ | Vol. 15 Issue 1 DOI 10.5195/jyd.2020.827 Youth Development Workforce

Norman, M. (2013). Using a hybrid approach for a leadership cohort program. Journal of Extension, 51(5). https://www.joe.org/joe/2013october/iw2.php

Peel, H. A., Wallace, C., Buckner, K. G., Wrenn, S. L., \& Evans, R. (1998). Improving leadership preparation programs through a school, university, and professional organization partnership. NASSP Bulletin, 82(602), 26-34.

Reynolds, K. C., \& Hebert, F. T. (1998). Learning achievements of students in cohort groups. Journal of Continuing Higher Education, 46(3), 34-43. https://doi.org/10.1080/07377366.1998.10400354

Shanahan, A. (2018). Take action with action learning: A valuable practice for navigating change. Journal of Extension, 56(4). https://joe.org/joe/2018august/tt6.php

Skuza, J., Grant, S., Harrington, R., Haugen, H., \& Pokorney, N. (2016). Minnesota 4-H youth development logic model. Saint Paul: University of Minnesota Extension.

Wenger, E. (2011). Communities of practice: A brief introduction. STEP Leadership Workshop. University of Oregon. Available at: http://hdl.handle.net/1794/11736

Wiedow, J. (2018). Supporting effective youth work: Job-embedded professional development in OST. Afterschool Matters. https://www.niost.org/images/afterschoolmatters/asm 2018 fall/ASM Fall18 YouthWork.pdf 